Genet. Res., Camb. (1962), 3, pp. 352-363

With 6 text-figures and 1 plate

Printed in Great Britain

\title{
Immunological analysis of incompatibility $(S)$ proteins and of cross-reacting material in a self-compatible mutant of Oenothera organensis
}

\author{
BY Y. L. A. MÄKINEN* AND D. LEWIS \\ Department of Botany, University College, London
}

(Received 14 June 1961)

\section{INTRODUCTION}

The inhibition of pollen-tube growth in an incompatible style in species with a gametophytic system of incompatibility is caused by an antigen-antibody type of reaction between a specific protein in the pollen and a protein with homologous specificity in the style. This mechanism has been deduced on theoretical grounds from the genetic system controlling incompatibility (East, 1929; Straub, 1947; Lewis, 1949). Direct experimental support for the antigen-antibody hypothesis has been obtained in two ways.

1. Antisera to pollen with different incompatible genotypes were produced, and by the precipitation technique antigens were found that were specific to the different pollen genotypes in Oenothera organensis (Lewis, 1952). This has been confirmed in Petunia by Linskens (1960) and extended to the proteins in the style.

2. A complex formed between pollen and stylar proteins was found in Petunia after the incompatible reaction had occurred in the pollinated style. This was shown by the use of radioactive tracers and paper electrophoresis (Linskens, 1958).

The role of these specific proteins in the growth of the pollen tube is still unknown. It has been suggested that the pollen protein is an enzyme essential for pollen-tube growth and that this enzyme is inactivated by homologous anti-enzyme in the style (Lewis \& Crowe, 1958; Linskens, 1960).

The present report is concerned with a further attempt to separate the specific proteins in pollen of Oenothera organensis with known incompatibility $S$ genes, using the Ouchterlony technique of agar diffusion. Certain genotypes such as homozygotes, $S_{6} S_{6}$, and self-compatible mutants, $S_{6^{\prime}} S_{6^{\prime}}$, have been included which were not available in the earlier precipitation studies. One of the main objectives was to test whether the self-compatible mutant, which lacks the specific incompatibility reaction between pollen and style, produces serologically cross-reacting material similar to the production of CRM by the $t d$ mutants of tryptophan synthetase in Neurospora (Suskind et al., 1955).

* Present address: Department of Botany, University of Turku, Turku, Finland. 


\section{MATERIAL AND METHODS}

\section{Source of pollen}

Pollen from five different incompatibility genotypes of Oenothera organensis were used for injections: $S_{2.3}, S_{2.6}, S_{3.6}, S_{4.6}, S_{6.6}$. The last one was represented by three different clones. In addition, pollen from genotypes $S_{2.4}$ and $S_{3.4}$ was used for the precipitation of test antigen solutions. The pollen was collected in the summer of 1959 as described by Lewis \& La Cour (1944), and stored in the deep-freeze at $-20^{\circ} \mathrm{C}$. In some tests, fresh pollen was also used which was collected in July 1960 , and either used at once or stored for some hours in the deep freeze.

\section{Injections}

The extracts for injections were prepared in saline $\left(0 \cdot 80 \% \mathrm{NaCl}, 0 \cdot 10 \% \mathrm{NaNO}_{3}\right)$ as described by Lewis (1952). The concentration used has $5 \%$ dry weight, which is equivalent to $c a .0 .75 \%$ protein. Injections were made into 11 rabbits as stated in Table 1. An adjuvent of $2 \mathrm{mg}$. $\mathrm{Al}(\mathrm{OH})_{3}$ per $\mathrm{ml}$ solution was used. Eight intravenous (without adjuvent) and two subcutaneous (with adjuvent) injections were made at weekly intervals with increasing amounts of solution ranging from 0.5 to $2 \mathrm{ml}$.

\section{Table 1. Details of injections}

(The brackets enclose the pollen obtained from the same clone)

\begin{tabular}{|c|c|c|c|}
\hline Rabbit & Pollen & $\begin{array}{l}\text { tal amou } \\
\text { of pollen } \\
\text { injected } \\
\text { (mg.) }\end{array}$ & Antiserum \\
\hline 1 & $S_{2.3}$ & 500 & No response \\
\hline 2 & $S_{2.6}$ & 350 & Weak antiserum \\
\hline 3 & $S_{3.6}$ & 500 & Weak antiserum \\
\hline 4 & $S_{3.6}$ & 500 & No response \\
\hline 5 & $\mathcal{S}_{3.6}$ & 500 & Weak antiserum \\
\hline 6 & $S_{3.6}$ & 500 & Strong antiserum \\
\hline 7 & $S_{4.6}$ & 401 & Very weak antiserum \\
\hline 8 & $S_{6.6}$ & 500 & Strong antiserum \\
\hline 9 & $S_{6.6}$ & 500 & Strong antiserum \\
\hline 10 & $S_{6.6}$ & 500 & Weak antiserum \\
\hline 11 & $S_{6.6}$ & 500 & No response \\
\hline
\end{tabular}

Two courses of injections were given with a rest period and a bleeding in between them. Before the injections, all animals were bled, and this antiserum gave entirely negative results with pollen extracts. To test the production of antiserum the animals were bled after the 5 th injection, but this antiserum was used only in some preliminary experiments. The rabbits were bled 2 weeks after the last injection either from the marginal vein or from the central artery of the ear. The blood, 20-30 ml. from each rabbit, was allowed to clot for 2 hours at room temperature, kept overnight in the refrigerator at $4^{\circ} \mathrm{C}$., centrifuged, and the antiserum was stored in the deep-freeze at $-20^{\circ} \mathrm{C}$. Pollen extracts were also stored at $-20^{\circ} \mathrm{C}$. 


\section{Test antigen solutions}

The test antigen solutions were made by macerating pollen in saline; the whole suspension was used without centrifugation. In some tests whole pollen suspension was used instead of the macerated suspension, without any difference in results. However, the macerated suspension is more practical to handle, allowing more accurate dilutions owing to the tendency to aggregate of the unmacerated pollen grains.

\section{Precipitation tests}

The precipitation tests were made by the method of Ouchterlony (1949), modified by Feinberg (1958). Eight millilitres of $0.9 \%$ New Zealand agar, prepared and clarified as described by Feinberg (1956), were poured into flat-bottomed $60 \mathrm{~mm}$. Petri dishes. In the clarification process, filtering through a Buchner funnel was not found necessary, and with $7 \mathrm{~g}$. of both bentonite and Celite Hyflo Super gel (L. Light \& Co. Ltd., London) in 1 litre of agar solution the clarification was completed in 24 hours at $56^{\circ} \mathrm{C}$. After setting, the wells were cut with Feinberg gel cutters supplied by Shandon Co., London, to get an even and standard spacing, and the pieces of agar were sucked off with a glass tube attached to a vacuum pump.

The antiserum was used undiluted, $0.2 \mathrm{ml}$. being placed in the central well. The surrounding wells were filled with antigen dilutions to such a point that the meniscus disappeared ( $c a .0 .02 \mathrm{ml}$.). Unless stated otherwise, the concentration of the antigen solutions was $1 \%$ of dry pollen, which is equivalent to $c a .0 \cdot 15 \%$ protein. The plates were marked with Alcian Blue, incubated, and after the precipitations were formed, the plates were washed thoroughly with saline, and stored in $70 \%$ alcohol. The drawings were made either from 'fresh' preparations or from plates stained with naphthalene black and dried. Prediffusion of the antiserum was not found necessary, because in this case the precipitation lines around the wells tended to curve so much that they did not touch each other.

\section{EXPERIMENTAL CONDITIONS}

\section{Influence of individual animals}

As can be seen in Table 1, there are considerable differences in responses between the animals. The variation is not only visible in the strength of the antiserum, but also in the number of precipitation lines. For example, the rabbits No. 8 and 9 , both injected with $S_{6.6}$ pollen, gave slightly different patterns. This could be due to the fact that the animals were not injected with isogenic pollen extracts. However these extracts, when used as test antigens, gave exactly similar patterns, and thus it is more probable that the difference depends on the animals. To eliminate these differences the tests were as a rule arranged so that one antiserum was tested with several antigens.

\section{Dilution}

In preliminary tests with different dilutions of antigens, the $1 \%$ pollen suspension was found to give the best results. The $5 \%$ suspension was so strong that the precipitations often failed to appear or were very weak owing to the excess of 
antigen. The $0 \cdot 1 \%$ suspension was, again, too weak, and the $0.5 \%$ suspension gave also slightly weaker precipitation lines than the $1 \%$ suspension (Text-fig. $1 a$ ). Because only a little pollen was available from the genotypes $S_{2.4}$ and $S_{3.4}$, the strongest solution of these types used was $0.1 \%$ and they were used only in some preliminary experiments.

\section{Incubation temperature}

Text-figures $1 b$ and $c$ reveal clearly the effect of incubation temperature. The other conditions being the same, only one line developed at $37^{\circ} \mathrm{C}$., and two lines at $26^{\circ} \mathrm{C}$. The precipitation lines are also sharper after the lower temperature. Weak antisera gave still better results at $4^{\circ} \mathrm{C}$. In this case, however, at least 1 week was needed before the lines began to appear. If not otherwise stated, an incubation temperature of $26^{\circ} \mathrm{C}$. was used throughout, in which case it took normally ca. 24 hours before the lines could be seen, but often 12 days were necessary for the lines to become fully developed.
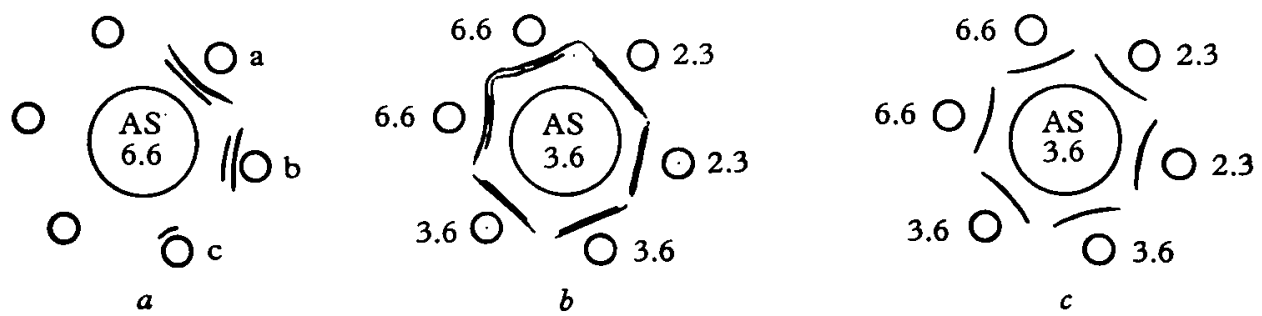

Text-fig. 1. Precipitation lines between antiserum (AS) and pollen antigens $(2.3,3.6$, etc.):

$(a)$ the effect of antiserum dilution, $(b)$ different antigens incubated at $26^{\circ} \mathrm{C}$., (c) the same antigens as $1 b$, at $37^{\circ} \mathrm{C}$. Antisera in $1 b$ and $1 c$ obtained after one course of injections.

\section{RESULTS OF PRECIPITATION EXPERIMENTS}

\section{Antiserum $\mathrm{S}_{\mathbf{2 . 6}}$}

This antiserum was quite weak, only weak precipitations were obtained at $26^{\circ} \mathrm{C}$, and no difference could be found between $S_{2.3}, S_{2.6}, S_{6.6}$ pollen, with which it was tested. At $4^{\circ} \mathrm{C}$. the lines were much sharper and clearer, the $S_{2.3}, S_{2.6}$ and $S_{3.6}$ lines were similar, but the precipitations with $S_{4.6}$ pollen were clearly stronger (Text-fig. 2a).

\section{Antiserum $\mathrm{S}_{\mathbf{3 . 6}}$}

With antiserum collected after the first course of five injections in preliminary experiments (Text-figs. $1 b$ and $c$ ) it was not possible to detect any real differences between $S_{2.3}, S_{3.6}$ and $S_{6.6}$ antigens. However, the $S_{6.6}$ lines were slightly stronger. Text-figures $2 b$ and $2 c$ illustrate two experiments with antiserum collected after the second course of injections, both of which show similar results. In both figures it is clearly visible that the $S_{3.6}$ lines do not join into the $S_{4.6}$ lines. The dissimilarity is also seen between the $S_{2.3}$ and $S_{4.6}$ lines in Text-fig. $2 b$ and between $S_{2.3}$ and $S_{6.6}$ in Text-fig. 2 c. In contrast, the lines between the $S_{2.3}$ and $S_{3.6}$ wells and between 
the $S_{4.6}$ and $S_{6.6}$ wells join each other. Thus two groups of pollen reacting types are obtained; these are summarized in Table 2. In this table, + means similarity between the precipitation lines, and - means dissimilarity.

Table 2. The similarity of pollen precipitatim lines: $\mathrm{S}_{2.3}$ and $\mathrm{S}_{3.6}$ react similarly, and $\mathrm{S}_{4.6}$ and $\mathrm{S}_{6.6}$ similarly

\begin{tabular}{|c|c|c|c|c|}
\hline & 2.3 & 3.6 & 4.6 & 6.6 \\
\hline 2.3 & + & + & - & - \\
\hline 3.6 & & + & - & - \\
\hline 4.6 & & & + & + \\
\hline 6.6 & & & & + \\
\hline
\end{tabular}

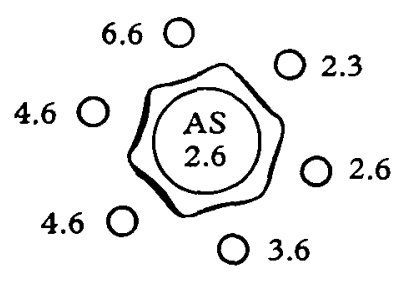

$a$

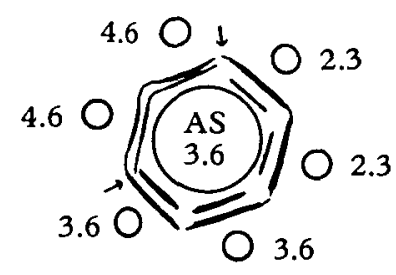

$b$

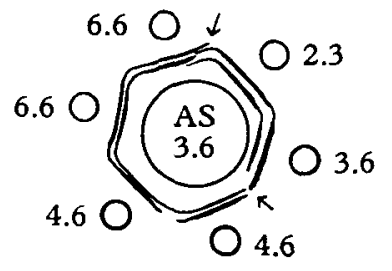

$c$

Text-fig. 2. (a) Precipitation lines with antiserum $S_{2.6}\left(b\right.$ and $c$ ) with $S_{3.6}$ entiserum; all second-course antisera.

\section{Antiserum $\mathrm{S}_{6.6}$}

The first-course antiserum gave stronger reactions with $S_{3.6}$ pollen than with homologous $S_{6.6}$ pollen. The second-course antiserum gave precipitations equally with $S_{3.6}$ and $S_{6.6}$ pollen. It is possible that all the antibodies in the $S_{6.6}$ serum which react with the $S_{6.6}$ pollen also react with the $S_{3.6}$ pollen, or alternatively that the increased precipitation with $S_{6.6}$ pollen and second-course antiserum may be due an antibody specific to the $S_{6.6}$ pollen which formed later in the course of the injections. In experiments with second-course antisera there was a difference between $S_{2.3}$ and $S_{3.6}$ pollen, these are shown in Text-fig. $3 a\left(37^{\circ} \mathrm{C}\right.$.) and $3 b\left(26^{\circ} \mathrm{C}\right.$.). Again the lower temperature gave a better separation of the precipitation lines. In Text-fig. $3 a$ there is only one small gap in the line between $S_{2.3}$ and $S_{3.6}$ pollen. This indicates that the cross reaction of $S_{2.3}$ pollen with the antiserum is not identical with the reaction of $S_{3.6}$ pollen. The explanation for this discontinuity may lie in the difference between $S_{2}$ and $S_{3}$. In Text-fig. $3 b$ there are additional lines on both sides of a common line. It is probable that the weaker inner line opposite the $S_{2.3}$ wells represents $S_{2}$ cross reacting with the antiserum and the outer lines opposite all the wells with $S_{3}$ pollen represent the $S_{3}$ antigen. The common line may be composed of both $S_{6}$ antigen and common antigens, i.e. those not specifically associated with the $S$ gene. 


\section{Antiserums $\mathrm{S}_{3.6}$ and $\mathrm{S}_{6.6}$}

When using a mixture of these two antisera placed in the central well, a marked increase in the lines is observed, as compared with either $S_{3.6}$ or $S_{6.6}$ antiserum alone (Text-fig. $3 c$ ). This indicates that either $S_{6.6}$ antiserum must contain some additional antibodies compared with $S_{3.6}$ antiserum, or the mixture of these two antisera does not react as a simple sum of the two separately. However, in this case, the precipitation lines are too complicated to explain in detail.

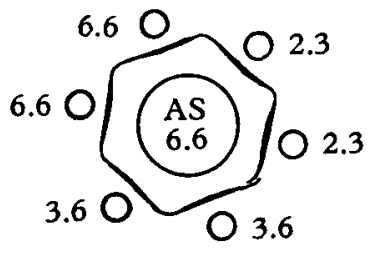

$a$

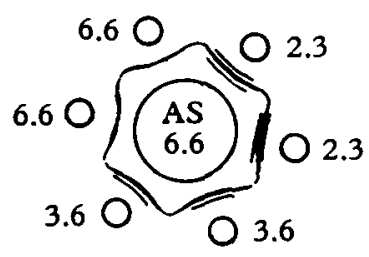

b

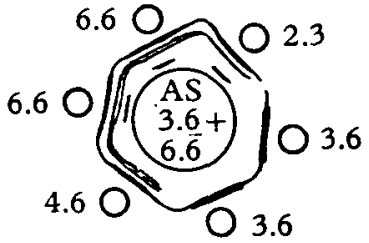

$c$

Text-fig. 3. (a) Incubated at $37^{\circ} \mathrm{C},(b)$ at $26^{\circ} \mathrm{C}$, (c) a mixture of two antisera $S_{3.6}$ and $S_{6 \cdot 6}$ incubated at $26^{\circ} \mathrm{C}$.

\section{The four-well test}

This is a sensitive test for detecting similarities and differences in antigens. In Text-fig. $4 a$, the lines show that, precipitated with $S_{3.6}$ antiserum, the line of pollen $S_{3.6}$ partly crosses the line of $S_{6.6}$ pollen. Thus it can be assumed that $S_{3.6}$ pollen contains an antigen, that is missing in pollen $S_{6.6}$, and this is probably caused by $S_{3}$. The same condition is seen in a different form between the pollen $S_{3.6}$ and antiserum $S_{6.6}$, and pollen $S_{6.6}$ and antiserum $S_{6.6}$, where $S_{3.6}$ pollen forms three, and $S_{6.6}$ pollen only two precipitation lines with $S_{6.6}$ antiserum. This result is comparable to Text-fig. $3 b$, in which $S_{3.6}$ pollen produced one more line than did $S_{6.6}$ pollen precipitated with the same antiserum. In accordance with the earlier explanation the third line is here caused by $S_{3}$ antigen. Text-figure $4 b\left(4^{\circ} \mathrm{C}\right.$.) reveals that little or no precipitation is formed between $S_{6.6}$ antiserum and pollen $S_{2.3}$. This is to be expected, because they do not contain common $S$-genes. The reason why quite a strong precipitation has formed between them in Text-fig. $3 b$ is that there is a much greater relative concentration of antiserum compared to the pollen, so that the antibodies are able to precipitate also the non-homologous antigens. The faint line repeatedly found between $S_{3}$ pollen and $S_{6}$ antiserum shows that there is a weak cross reaction between $S_{3}$ and $S_{6}$, which is revealed under optimal conditions.

At $26^{\circ} \mathrm{C}$. the precipitation pattern differs from the $4^{\circ} \mathrm{C}$. pattern (Text-fig. $4 \mathrm{c}$ ). There is now a clear difference between $S_{3.6}$ and $S_{6.6}$ antiserum precipitated with $S_{3.6}$ pollen, antiserum $S_{3.6}$ forms two lines one of which is missing in the precipitation between antiserum $S_{6.6}$ and pollen $S_{3.6}$. Precipitation between antiserum $S_{3.6}$ and pollen $S_{4.6}$ is much weaker than between the same antiserum and pollen $S_{3.6}$, because in the first case there is only common antgen. 


\section{Absorption tests}

Precipitation experiments were attempted also with absorbed antisera (see Lewis, 1952, p. 129), but they yielded no precipitates. Obviously the pollen extracts are, under certain conditions, capable of removing also the non-homologous antibodics from the antisela. In tests where the poilen extracts or suspensions were embedded in agar (Feinberg, 1958, p. 198) no precipitations were obtained.

With the uniform antibody concentration technique of Feinberg (1958, p. 198), where the antiserum is mixed with the agar, the following results were obtained (antiserum was used at $0.8 \mathrm{ml}$. per plate):

AS

6.6

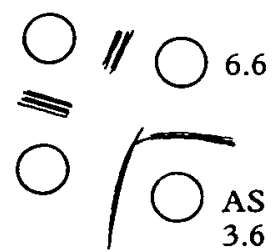

$a$
AS

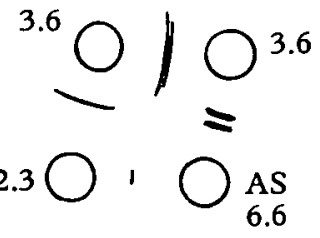

$b$

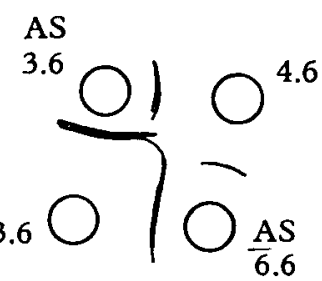

c

Text-fig. 4. The four-well test, antisera, $S_{6.8}$ and $S_{8.6}$ are placed in separate wells and pollen antigens in the two outer wells, $(a$ and $c) 26^{\circ} \mathrm{C}$., $(b) 4^{\circ} \mathrm{C}$.

(a) Antiserum $\mathrm{S}_{3.6}$ in agar

Plate I illustrates one experiment, in which the antiserum $S_{6.6}$ was put into the central well, and pollen extracts into the surrounding wells. Here the many concentric rings around the wells $3.6,4.6$ and 6.6 and the weak rings around the wells

Table 3. Antigens and antisera used in the experiment shown in Plate 1. A: antigens causing precipitation rings round small wells; $B$ : antigens remaining after precipita-

tion; $C$ : remaining antigens that are homologous with antibodies in central well

\begin{tabular}{|c|c|c|c|c|c|}
\hline \multirow{3}{*}{$\begin{array}{c}\text { Pollen } \\
\text { type }\end{array}$} & \multicolumn{2}{|c|}{ Antisera } & \multirow{2}{*}{\multicolumn{3}{|c|}{ Antigens }} \\
\hline & & in centrel & & & \\
\hline & in agar & well & $\mathbf{A}$ & B & C \\
\hline 2.3 & 3.6 & 6.6 & 3 & 2 & - \\
\hline 2.6 & 3.6 & 6.6 & 6 & 2 & - \\
\hline 3.6 & 3.6 & 6.6 & 3.6 & - & - \\
\hline 4.6 & 3.6 & 6.6 & 6 & 4 & - \\
\hline 6.6 & 3.6 & 6.6 & 6.6 & - & - \\
\hline
\end{tabular}

2.3 and 2.6 are clearly visible. Again, as also in experiments illustrated in Table 2 with $S_{3.6}$ antisera, $S_{4.6}$ and $S_{6.6}$ pollen react similarly. The rings are weaker between the outer wells; this is due to the excess of antigens at these points. For the same reason, in many experiments the rings tended to lengthen towards other antigen wells.

The theoretical expectations in this experiment are collected in Table 3. 

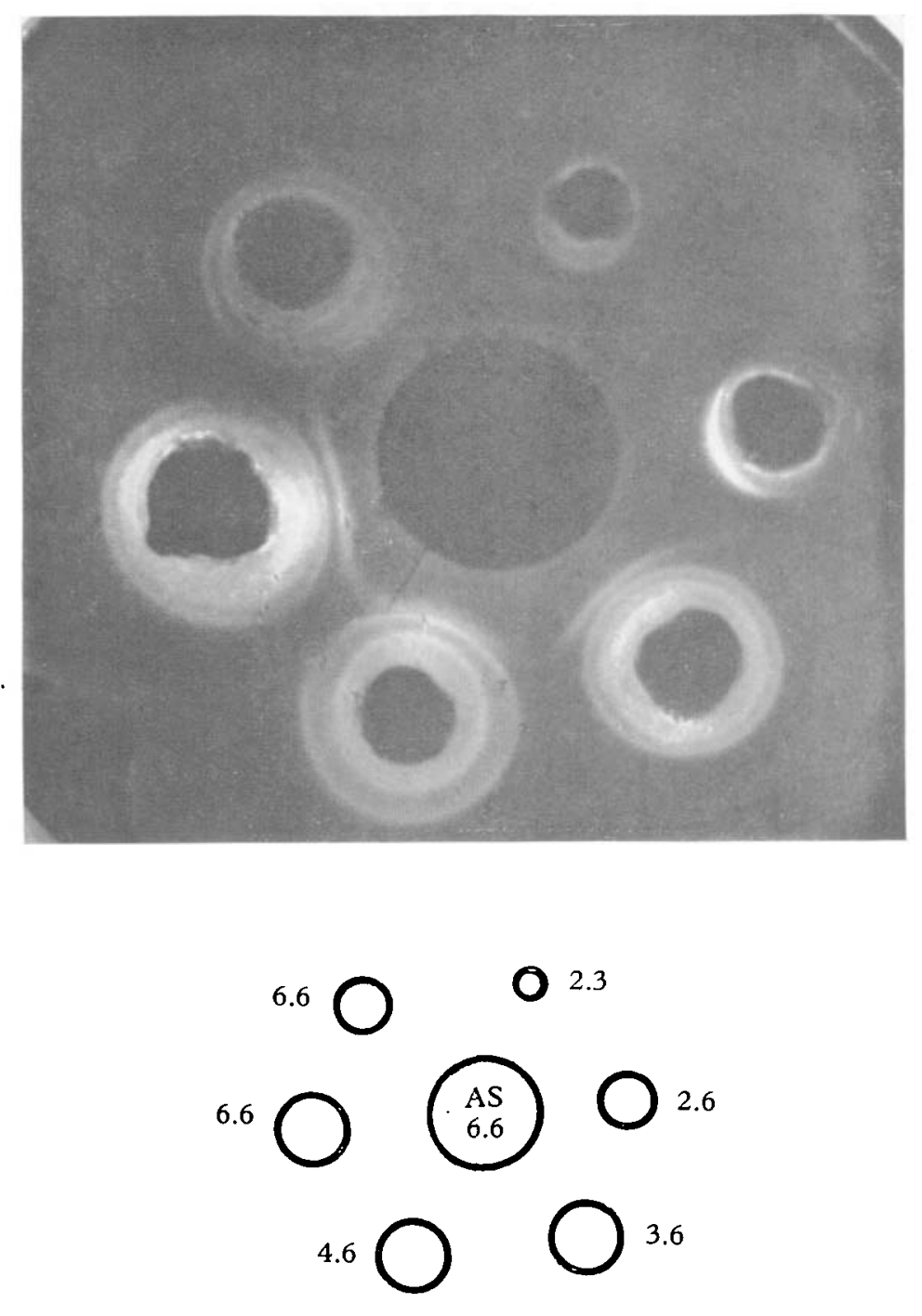

As 3.6 in agar

Plate I. Plate with $S_{3.6}$ antiserum in the agar, antiserum $S_{6,6}$ in the central well and pollen $S_{2.3}$ in $1, S_{2.6}$ in $3, S_{4.6}$ in 4 and $S_{6.6}$ in wells 5 and 6 . Note the large circles of precipitate round wells $3.6,4.6$ and 6.6 . 
The results are in reasonable agreement with the expectations. The rings around the wells 2.3 and 2.6 are very small, due to the presence of only one dose of homologous antigen. Around the wells 3.6 and 6.6 the rings are large due to the presence of two doses of homologus antigen. The only exception is with pollen $S_{4.6}$, which reacts like $S_{3.6}$ and $S_{6.6}$, and not as $S_{2.3}$, as it should. It seems as if the $S_{4}$ were reacting like $S_{3}$ or $S_{6}$.

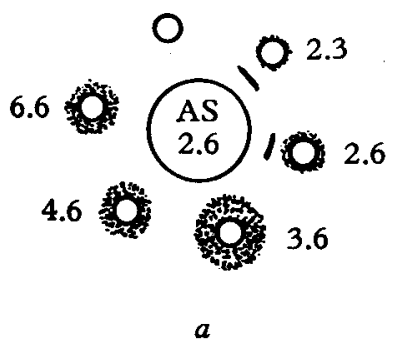

Antiserum 3.6 in agar

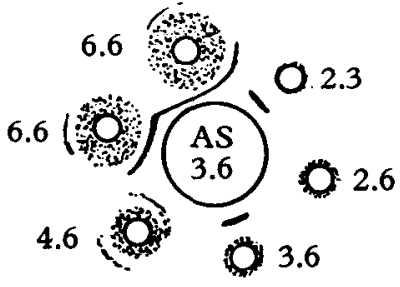

$b$

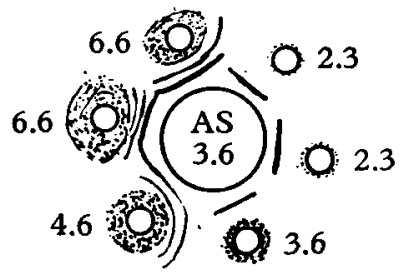

$c$

Antiserum 6.6 in agar Antiserum 6.6 in agar

Text-fig. 5. Absorption experiment with antiserum in the agar and a different antiserum in the centre well. Note the different areas of precipitate, and the lines of precipitate between outer wells and the centre when there is a $S$ allele common to centre and outer wells and which is absent from the agar.

The concentric rings around the wells could be due to different antibody-antigen systems, but it is more probable that they represent only successive rings of the same system (see Feingerg, 1957). The precipitation line which appears nearest to the central well is probably due to $S_{3.6}$ antiserum in the agar and $S_{6.6}$ antiserum in the central well.

Text-figure $5 a$ illustrates the same type of experiment, but with antiserum $S_{2.6}$ in the central well, and Table 4 again shows the theoretical precipitations.

Table 4. Antigens and antisera used in the experiment shown in Fig. 5a. A : antigens causing precipition rings round small wells; $B$ : antigens remaining after precipitation; $C:$ remaining antigens that are homologous with antibodies in central well

$\begin{array}{ccclccc}\begin{array}{c}\text { Pollen } \\ \text { type }\end{array} & \overbrace{\text { in agar }}^{\text {in central }} \begin{array}{c}\text { Avell } \\ \text { intisera }\end{array} & \overbrace{\mathrm{A}}^{\mathrm{A}} & \mathrm{B} & \mathrm{C} \\ 2.2 & 3.6 & 2.6 & 3 & 2 & 2 \\ 2.6 & 3.6 & 2.6 & 6 & 2 & 2 \\ 3.6 & 3.6 & 2.6 & 3.6 & - & - \\ 4.6 & 3.6 & 2.6 & 6 & 4 & - \\ 6.6 & 3.6 & 2.6 & 6.6 & - & -\end{array}$

In accordance with this Table, quite large precipitation rings were formed around the wells 3.6, 4.6 and 6.6, and rather smaller ones around 2.3 and 2.6. Pollen $S_{4.6}$ is again an exception. Precipitation lines with the antiserum in the central well are visible only between the wells 2.3 and 2.6 and the central well, as also expected in Table 4. 
(b) Antiserum $\mathrm{S}_{6.6}$ in agar

The theoretical expectations, using antiserum $S_{3.6}$ in the central well, are shown in Table 5, and the results are seen in Text-fig. $5 b$ :

Table 5. Antigens and antibodies used in the experiment shown in Fig. $5 \mathrm{~b}$. $A$ : antigens causing precipitation rings round smallwells; $B$ : antigensremainingafter precipitation;

$C$ : remaining antigens that are homologous with antibodies in central well

Antisera

\begin{tabular}{|c|c|c|c|c|c|}
\hline \multirow{3}{*}{$\begin{array}{c}\text { Pollen } \\
\text { type }\end{array}$} & \multicolumn{2}{|c|}{$\overbrace{}^{\prime}$} & \multicolumn{3}{|c|}{ Antigens } \\
\hline & & in central & & & \\
\hline & in agar & well & $\mathbf{A}$ & B & C \\
\hline 2.3 & 6.6 & 3.6 & - & 2.3 & 3 \\
\hline 2.6 & 6.6 & 3.6 & 6 & 2 & - \\
\hline 3.6 & 6.6 & 3.6 & 6 & 3 & 3 \\
\hline 4.6 & 6.6 & 3.6 & 6 & 4 & - \\
\hline 6.6 & 6.6 & 3.6 & 6.6 & - & - \\
\hline
\end{tabular}

In accordance with expectations, the precipitation rings around wells 2.6 and 3.6 are small (due to only one antigen), and around well 2.3 the rings are very small (no common $S$-antigens), and the rings around wells 6.6 very large. $S_{4.6}$ pollen is again an exception. Precipitation lines with the central antiserum only appear, as expected, between the wells 2.3 and 2.6 and the central well, whereas other precipitation lines are due to both $S_{6.6}$ antiserum in the agar, and $S_{3.6}$ antiserum in the central well. Text-figure $5 c$ illustrates a similar experiment.

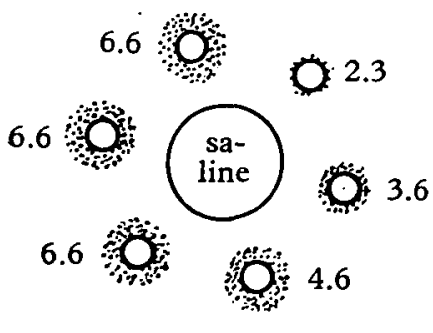

$a$

Antiserum 6.6 in agar

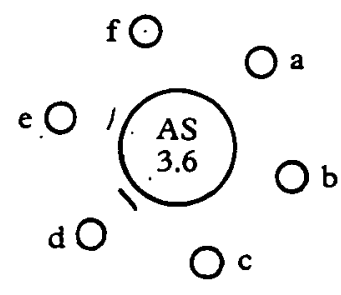

$b$

$$
\begin{gathered}
\text { a-c: } \begin{array}{c}
\text { Oenothera } \\
\text { lamarckiana } \\
\text { d-f: Chamaenerium } \\
\text { angustifolium }
\end{array} \\
\text { a,d: } 1: 20 \\
\text { b,e: } 1: 100 \\
\text { c, f: } 1: 1000
\end{gathered}
$$

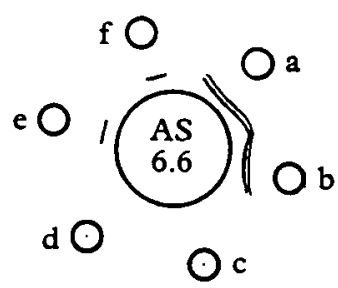

$c$

$\mathrm{ab}: 6.6$

cd: Oenothera

lamarckiana

ef: Chamaenerium

angustifolium

Text-fig. 6. (a) Precipitations with antiserum $S_{6.6}$ in the agar, ( $b$ and $c$ ) reactions between Oenothera organensis antisera $S_{3.6}$ and $S_{6.6}$ and $O$. lamarckiana and Chamaenerium angustifolium.

In the experiment illustrated in Text-fig. $6 a$ saline was put into the central well instead of antiserum. The size of the precipitation rings agrees with expectation, and the lines between the surrounding wells and the central well are totally absent. 


\section{Self-compatible mutant $\mathrm{S}_{6^{\prime}}$}

The pollen of a family of plants derived from a self-compatible mutant was tested with $S_{6.6}$ antiserum. The $S$ allele which produces the self-compatible character is $S_{6^{\prime}}$. It was derived by mutation from $S_{6}$, it produces the normal $S_{6}$ incompatibility reaction in the style but does not produce any incompatibility reaction in the pollen. Genetical evidence has been obtained that a specific pollen protein is produced by $S_{6^{\prime}}$, but this is not active in the incompatibility reaction (Lewis, 1960). Pollen of plants which were $S_{6^{\prime} \cdot 6^{\prime}}$ and $S_{6^{\prime} .6}$ were tested against $S_{6.6}, S_{2.3}$ and $S_{3.6}$ antiserum and found to give strong precipitation lines, with $S_{6.6}$ and $S_{3.6}$ which were identical with those produced by $S_{6}$ pollen. This confirms the previous interpretation that $S_{6}$ produces an inactive but cross reacting protein.

\section{Interspecific tests}

Some precipitation tests were made with Oenothera organensis antiserum and pollen of some other Oenothera and even Chamaenerium species. In experiments with $O$. lamarckiana and $C$. angustifolium the former gave no precipitations, but the latter gave a weak line in the concentration $5 \%$ dry pollen and a still weaker line in $1 \%$ pollen suspension (Text-fig. $6 b$ ). Text-figure $6 c$ shows the difference between these precipitation lines and the lines obtained with homologous $S_{6.6}$ pollen.

\section{ELECTROPHORESIS}

Electrophoretic separation of pollen proteins was carried out using both agar and cellulose acetate strips. The latter gave clearly the better results. A maximum number of eight lines was obtained after electrophoresis at 5 hours/120 V./1.5 mA. but there was only one strong line. No difference could be found between different incompatibility genotypes. At $\mathrm{pH} 8.6$ (veronal buffer) all the proteins moved in the positive direction, at $\mathrm{pH} 5 \cdot 6$ (phosphate-citrate buffer) only 3-4 lines were obtained, one of which moved towards the cathode, and one remained stationary.

\section{DISCUSSION}

The precipitation lines obtained in the agar plates with Oenothera pollen confirm the early results obtained with the relatively insensitive precipitin ring technique, and show that there are protein fractions in the pollen with serological specificities that are determined by incompatibility $S$ alleles. Staining tests and heat denaturation on pollen extracts and on exudates into the agar indicated that the antigenic substance is a protein but this does not exclude the presence of a small component of polysaccharide. The tests showed that this $S$ protein is a substantial part of the total protein which can be readily dissociated in saline from the macerated cell fragments. In the agar-gel tests the same precipitation lines of equal intensity were produced with macerated pollen or with intact pollen. This must mean that the $S$ proteins readily diffuse out of the pollen grain; a fact which indicates that the normal place of action of the $S$ protein, when the pollen tube is growing down the style, is either on the surface of the pollen tube or is outside in the stylar tissue. 
When pollen tubes are growing down the style incompatible and compatible tubes may often be contiguous, but there is no influence of one on the other. This supports the view that the $S$ protein has its place of action on the surface of the pollen tube and not outside in the style.

The detection of an $S$ protein which cross reacts with $S_{6}$ antiserum in poilen of the self-compatible mutant of $S_{6^{\prime}} S_{6^{\prime}}$ genotype, in which the $S_{6^{\prime}}$ allele is unable to make active $S$ pollen antigen, is of importance in the interpretation of the mutational change from $S_{6}$ to $S_{6^{\prime}}$ and in the role of the $S$ protein in pollen tube growth.

It had been deduced from genetic complementation tests that this mutational change affects only the activity of the $S$ gene product and not its unique $S_{6}$ specificity, which is different from all the other normal $S$ alleles. This deduction was based upon two observations: (1) The $S_{6^{\prime}}$ allele produces its unique $S_{6}$ specificity in the style, and (2) the action of $S_{6}$ is restored to full $S_{6}$ activity in a diploid pollen grain when in the presence of a normal allele, for example $S_{2}$ (Lewis, 1960). The presence of cross-reacting material in $S_{6^{\prime}}$ pollen supports the hypothesis that the $S$ gene or gene complex of two cistrons, has at least two separate series of sites, one set specifying the precise pattern of the protein which confers its unique incompatibility and serological reaction and another which determines the activity of the protein.

The presence of cross-reacting material raises the question of the role of the $S$ protein in normal pollen-tube growth. If the $S$ protein is an enzyme essential for normal pollen-tube metabolism and growth, then cross-reacting material must be present if the pollen is viable in a compatible cross. On this basis the activity lost by mutation to $S_{6^{\prime}}$ must affect only the ability of the pollen protein to react with the homologous stylar protein which causes the incompatibility reaction. If on the other hand the $S$ protein is not an essential enzyme but forms an inhibitor of normal pollen metabolism when it reacts with the homologous style protein, then the absence of cross-reacting material is a possibility.

The presence of cross-reacting material in $S_{6^{\prime}}$ and the extreme localization of the inhibiting effect on individual pollen tubes support the enzyme:anti-enzyme hypothesis.

\section{SUMMARY}

Proteins of pollen of Oenothera organensis from heterozygous $S_{2} S_{3}, S_{2} S_{6}, S_{3} S_{6}$ and $S_{4} S_{6}$ and homozygous $S_{6} S_{6}$ genotypes produce characteristic precipitation lines in agar-gel plates against antisera prepared from the pollen. The maximum number of precipitation lines was three, and with some genotypes only one line was formed. The lines were characteristic of the different $S$ alleles, but there was a strong cross-reaction between $S_{4}$ pollen and $S_{6}$ antiserum. The $S$ protein diffused out from intact pollen grains as readily as from macerated pollen indicating that the normal site of action of the $S$ protein, when the pollen tubes are growing down the style, is near the surface of the pollen tube. The self-compatible mutant $S_{6} S_{6}$ in which the $S_{6}$, allele has lost the ability to produce an active pollen $S$ protein, has a protein which cross-reacts strongly with $S_{6}$ antiserum. 
We wish to thank Prof. Sir Lindor Brown for very kindly arranging for accommodation for the animals in the Physiology Department of University College, London. We also wish to thank the British Council for the financial support of this work.

\section{REFERENCES}

EAST, E. M. (1929). Self sterility. Bibliogr. Genet. 5, 331-370.

FeINBERG, J. G. (1956). Agar clarification. Nature, Lond., 178, 1406.

FenNberG, J. G. (1957). Identification, discrimination and quantification in Ouchterlony gel plates. Int. Arch. Allergy, 2, 129-152.

Fennberg, J. G. (1958). Specific titration of biological solutions in agar gel plates. 4th Int. Congr. Biol. Stand, Brussels, pp. 194-221.

LEwIS, D. \& LA CoUR, L. F. (1944). Collection of pollen and artificial wind pollination. Nature, Lond., 153, 167.

LEwIS, D. (1949). Incompatibility in flowering plants. Biol. Rev. 24, 472-96.

LEwIS, D. (1952). Serological reactions of pollen incompatibility substances. Proc. roy. Soc. $\mathrm{B}, 140,127-135$.

LewIS, D. (1960). Genetic control of specificity and activity of the $S$ antigen in plants. Proc. Roy. Soc. B., 151, 468-477.

LEwIS, D. \& Crowe, L. K. (1958). Unilateral interspecific incompatibility in flowering plants. Heredity, 12, 233-256.

Linskens, H. F. (1958). Zur Frage der Enstehung der Abwehr-Körper bei der Inkompatibilitäts-reaktion von Petunia I. Ber. dtsch. bot. Ges. 71, 3-10.

Linskens, H. F. (1960). Zur Frage der Enstehung der Abwehr-Körper bei der Inkompatibilitäts reaktion von Petunia III. Z. Bot. 48, 126-135.

Odchterlony, O. (1949). Antigen-antibody reactions in gels. Acta path. microbiol. 26, $507-515$.

Straub, J. (1947). Zur Entwicklungsphyiologie der Sebststerilät von Petunia II Das Prinzif des Hemmungsmechanismus. $Z$. Naturf. 2b, 433-444.

SUSkTND, S. R., YANOFSKY, C. \& BonNER, D. M. (1955). Allelic strains of Neurospora lacking tryptophan synthetase: a preliminary immunochemical characterization. Proc. nat. Acad. Sci., Wash., 41, 577-582. 